\title{
MATHEMATICAL MODELLING IN ELECTRICAL ENGINEERING ${ }^{1}$
}

\author{
L. HA̧CIA \\ Poznan University of Technology, Institute of Mathematics \\ 60-965 Poznan ul.Piotrowo 3A \\ E-mail: lhacia@math.put.poznan.pl
}

Received August 30, 2004; revised July 10, 2005

\begin{abstract}
Various problems of electrical engineering lead to mathematical models being difference, differential or integral equations. In this paper some mathematical models in certain problems of electrical engineering are presented. Our considerations are restricted to the radiative heat transfer and density theory (Fredholm integral equations). Respecting time in current density problems we get integro-differential equations or generally Volterra-Fredholm integral equations (heat-conduction theory). The new numerical method for these equations is analysed.
\end{abstract}

Key words: mathematical modelling, electrical engineering

\section{Introduction}

The paper emphasizes advantages of the method of integral equations (MIE) in various branches of technology, with special attention paid to power engineering. These problems usually lead directly to integral equations or integrodifferential equations. The numerical methods for a general class of integral equations in space-time (Volterra-Fredholm integral equations) will be presented. Many power-engineering problems including time-dependent models may be reduced to such class of problems. We restrict to some integral mathematical models in electrotechnics. The report analyses the methods of numerical solutions of various tasks defined in the terms of boundary-initial value problems of differential or integral equations. In natural and technical sciences mathematical models are defined by differential equations and solved mostly by using finite-difference method (FDM), finite-element method (FEM), boundary-element method (BEM).

\footnotetext{
${ }^{1}$ The author is thankful to the editor and the referees for useful remarks improving this paper.
} 
A choice of calculation method is affected by many factors. First of all, it is determined by the possibility of accurate definition of the problem, including its formulation and specification of boundary-initial conditions. It depends as well on the system of algebraic equations and parameters of computer hardware used for carrying out the task.

The FDM is the oldest, the simplest, and the most popular method, based on replacing finite differences for derivatives. It was formulated as an approximate discrete method for solving boundary-value problems defined in terms of differential equations. Furthermore, its application was widened to variational problems. It may be used as well for boundary-initial value problems related to differential equations of parabolic type, describing temperature distribution in the theory of heat conduction. Therefore, it is usually applied to internal problems. It might be also used for external problems but leads to huge systems of equations, as the elements must cover the whole field of analysis.

Recently the BEM approach is very often used for solution of mechanical problems. It leads to considerable reduction of the number of equations. It appears very advantageous, as for solving large systems of equations, since large computer memory size is required and the process itself is much labourconsuming. Success of the method consists in omitting of discretization of the field. Only its border is subject to discretization, causing reduction of the dimension size by unity and lowering the computation time. The FEM and BEM approaches might be considered as complementary as their faults and advantages compensate each other. Extensive work aimed at connecting of both methods lead to hybrid techniques joining advantages of both and eliminating their faults.

The work presents advantages of the method of integral equations and possibility of its application to various branches of technology, particularly to the problems arising in comprehensively understood power engineering. It is an analytical-numerical method and requires deep engagement of highly skilled specialists (mathematicians, specialists of numerical and computer sciences, engineers).

Taking into account growing popularity of integral equations, the present paper is devoted to the most modern methods of numerical solving of wide class of integral equations in space-time, called the Volterra-Fredholm equations. It should be noticed that the algorithms provided here can be in particular applied for integral equations of both Volterra and Fredholm types. In this paper we restrict to mathematical models describing the radiative heat transfer, the density theory and the heat conduction problems.

\section{Radiative Heat Transfer}

The problem of proper radiative heat transfer analysis [6] takes place when considering issues related to heat transfer in electrotechnical equipment and in luminous flux transfer in confined space. Luminous flux transfer can be 
regarded as a specific (limited to the visible range) case of optical radiation transfer. Both radiative thermal flux transfer governed by laws of thermodynamics and luminous flux transfer governed by laws of lighting engineering can be solved using the same calculation methods.

For any body taking a "passive" part in radiative transfer, i.e. for a body, which does not emit radiation in a given range there must be a balance of radiant (flux) power - both for the stationary stage and for the scope of radiation being analysed. This means that monochromatic $(\lambda)$, spectral $(\Delta \lambda)$ or total (c) radiant flux striking a body must be equal to the total sum of the reflected $\left(P_{r-r}\right)$, absorbed $\left(P_{r-a}\right)$ and $\left(P_{r-t}\right)$ transferred flux, respectively.

When considering and incident wave (ray) or beam of waves (rays) incident on any body, reflected radiation and transferred radiation can be regular (specular), diffused (Lambertian) or mixed. Therefore, if a wave strikes an elementary surface whose unevenness is significantly smaller than the wavelength of the wave, and a beam strikes a surface (consisting of elementary surfaces) void of macroscale - compared to the width of beam - unevenness and if the body is optically homogeneous (non-diffusing) or optically non-homogeneous but highly suppressing (e.g. metal), then the reflected radiation of such wave (beam) can be regarded as specular. In other cases such radiation is mixed (non-diffuse) or close to diffuse (Lambertian) radiation.

For diffusing bodies the degree of diffusion of reflected and transmitted radiation depends on the spectral distribution of incident radiation and the incident direction thereof. Thus, the reflectance, absorption and transmittance of the body are not invariable features of the body, rather they depend on the direction and spectral distribution of the incident radiation and, additionally, on the body's energy state and - for translucent bodies - on the dimensions thereof.

Bodies which are "active", from the radiation point of view can radiate in a specular, mixed or diffused way. Examples of such bodies for visible radiation are light sources or luminaries, for monochromatic optical radiation are quantum radiation amplifiers, for total or optionally spectral thermal radiation radiant flux are radiating bodies across the whole or selected wavelength. In the case of thermal radiation the value of monochromatic, spectral or total radiant flux is directly proportional to the value of the monochromatic $\varepsilon_{\lambda}$, spectral $\varepsilon_{\Delta \lambda}$ or total $\varepsilon_{c}$ emissivity. Values of individual above mentioned emissivity factors, being a function of wavelength and direction, depend additionally on the energy state of the radiating body (e.g. temperature) and for translucent bodies - on the dimensions.

Actual transfers of optical radiations (including visible ones) are extremely complicated and can be presented by the following formula

$$
\begin{aligned}
p_{e f, \lambda}\left(x, T, \theta_{0}, \phi_{0}\right)=p_{e, \lambda} & \left(x, T, \theta_{0}, \phi_{0}\right) \\
& +\int_{\Omega} \rho_{b d, \lambda}\left(x, \theta_{0}, \phi_{0}, \theta, \phi\right) p_{i, \lambda}\left(x, T_{i}, \theta, \phi\right) \cos \theta d \omega
\end{aligned}
$$


where $p$ is surface contained within the elemental solid angle $d \omega,(\theta, \phi)$, monochromatic $(\lambda)$ spectral radiance are defined at point $x, T$ is temperature, effective $(e f)$, emitted $(e)$ and incident $(\mathrm{i}) ; \rho_{b d}$ is bi-directional reflectance distribution function $\mathrm{BRDF}$, or by formula

$$
L_{\lambda}\left(x, \theta_{0}, \phi_{0}\right)=L_{e, \lambda}\left(x, \theta_{0}, \phi_{0}\right)+\int_{\Omega} \rho_{b d, \lambda}\left(x, \theta_{0}, \phi_{0}, \theta, \phi\right) L_{i, \lambda}(x, \theta, \phi) \cos \theta d \omega,
$$

where $L$ is monochromatic $(\lambda)$ luminance at point $x$ in direction $(\theta, \phi)$, contained within the elemental solid angle $\mathrm{d} \omega$.

The above problems lead to systems of Fredholm integral equations [1].

\section{The Density Theory}

\subsection{The current density in the conductor with rectangular cross-section}

Let us consider the conductor of infinite length on arbitrary cross-section situated parallel to $z$-axis of the rectangular coordinate systems. The current density $J(x, y)$ inside of the conductor is a solution of the following Fredholm integral equation of the second kind [6]

$$
J(x, y)-J\left(x_{0}, y_{0}\right)+\frac{j \omega \mu_{0} \gamma}{2 \pi} \iint_{S} J(u, v) \ln \sqrt{\frac{\left(x_{0}-u\right)^{2}+\left(y_{0}-v\right)^{2}}{(x-u)^{2}+(y-v)^{2}}} d u d v=0
$$

where $\mu_{0}$ means the magnetic inductive capacity, $\gamma$ is conductivity, $x_{0}, y_{0}$ are coordinates of relation point, $S$ is cross-section of the conductor.

Additionally condition

$$
\iint_{S} J(u, v) d u d v=I
$$

guarantees uniqueness of solution for that problem.

$S$ is discretized by using uniform rectangular elements $\Delta S_{1}, \Delta S_{2}, \ldots, \Delta S_{N}$ with middle points $\left(x_{m}, y_{m}\right), m=1,2, \ldots, N$. Assuming that the center of element $\Delta S_{N}$ is a relative point, i.e. $x_{0}=x_{N}$ and $y_{0}=y_{N}$, the given integral equation can be reduced to $N l$ algebraic linear equations

$$
\sum_{n=1}^{N} l_{m n} J_{n}=0
$$

where $J_{n}$ means approximate value of the current density in element $\Delta S_{n}$, and 


$$
l_{m n}=\delta_{m n}-\delta_{n N}+\frac{j \omega \mu_{0} \gamma}{2 \pi} \iint_{\Delta S_{n}} \ln \sqrt{\frac{\left(x_{N}-u\right)^{2}+\left(y_{N}-\nu\right)^{2}}{\left(x_{m}-u\right)^{2}+\left(y_{m}-\nu\right)^{2}}} d u d v=0
$$

for $m=1,2, \ldots, N-1 ; n=1,2, \ldots, N, \delta_{m n}$ is Kronecker's delta.

Respecting the condition (3.1) we get the approximation

$$
\sum_{n=1}^{N} J_{n} \Delta S=I
$$

Hence

$$
\sum_{n=1}^{N} J_{n}=\frac{I}{\Delta S}
$$

Equations (3.2) and (3.3) form the system of $N l$ linear algebraic equations, which can be described in the form

$$
\left[\begin{array}{cccc}
l_{11} & l_{12} & \cdots & l_{1 N} \\
l_{21} & l_{22} & \cdots & l_{2 N} \\
\cdots & \cdots & \cdots & \cdots \\
l_{N-1,1} & l_{N-1,2} & \cdots & l_{N-1, N} \\
1 & 1 & 1 & 1
\end{array}\right]\left[\begin{array}{c}
J_{1} \\
J_{2} \\
\vdots \\
J_{N-1} \\
J_{N}
\end{array}\right]=\left[\begin{array}{c}
0 \\
0 \\
\vdots \\
0 \\
I / \Delta S
\end{array}\right]
$$

Remark 1. Similar results may be presented for few conductors.

\subsection{Nonstationary current density}

Analysis of the current density leads to the system of integral equations of the Fredholm type [6]. This problem is time-dependent and provides the mathematical model determined by the system of integro-differential equations [5].

Consider the conductor of infinite length on arbitrary cross-section $S$ situated parallel to $z$-axis of the rectangular coordinate systems. The current vector $\boldsymbol{J}$ and the magnetic vector potential $\boldsymbol{A}$ are parallel to the $z$-axis and independent of $z$. Thus the problem is two-dimensional

$$
\boldsymbol{J}=\boldsymbol{I}_{z} J(x, y, t), \quad \boldsymbol{A}=\boldsymbol{I}_{z} A(x, y, t) .
$$

Assuming that magnetic inductive capacity is given by $\mu_{0}$ and conductivity by $\gamma$, the magnetic vector potential satisfies:

$$
\Delta^{2} \boldsymbol{A}=\boldsymbol{l}_{z} \Delta^{2} A(x, y, t)=\left\{\begin{array}{cl}
-\mu_{0} \boldsymbol{l}_{z} J(x, y, t) & \text { inside the conductor } \\
0 & \text { outside the conductor. }
\end{array}\right.
$$

The solution of this equation has the following form 


$$
A(x, y, t)=\frac{\mu_{0}}{2 \pi} \int_{S} J\left(x^{\prime}, y^{\prime}, t\right) \ln \frac{1}{r} d x^{\prime} d y^{\prime},
$$

where

$$
r=\sqrt{\left(x-x^{\prime}\right)^{2}+\left(y-y^{\prime}\right)^{2}}
$$

is a distance between the source filament $\left(x^{\prime}, y^{\prime}\right)$ and the field point $(x, y)$.

The electric intensity is conveniently found from:

$$
\boldsymbol{E}=-\frac{\partial \boldsymbol{A}}{\partial t}-\operatorname{grad} V
$$

For $2 \mathrm{D}$ case equation (3.4) reduces to

$$
\boldsymbol{E}=-\frac{\partial \boldsymbol{A}}{\partial t}
$$

Then the above problem leads to system of integro-differential equations (see [5]), which after discretization gives the approximate distribution of the current density.

In Figure 1 numerical results for the distribution of the current density at time $t=0.01 \mathrm{~s}$ are presented. The remaining parameters of the model are the following: the size of the conductor is $1 \mathrm{~cm} \times 1 \mathrm{~cm}$, the conductivity $\gamma=$ $56 M S / m$ and the current $i(t)=100 t$. The number of rectangular subsections $\Delta S$ was equal to 625 elements $\left(N_{x}=N_{y}=25\right)$.

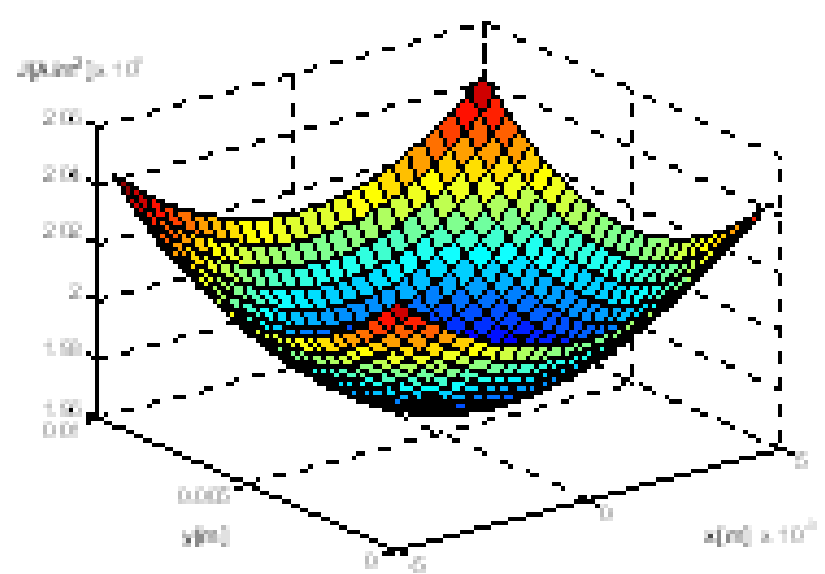

Figure 1. The distribution of the current density for $t=0.001 \mathrm{~s}$.

Remark 2. The above problem can be extended for few conductors. 


\section{Mathematical Models in the Heat-Conduction Theory}

The problems of the heat conduction theory and diffusion theory are of great importance in technology and engineering sciences. The same mathematical model, i.e. the parabolic initial-boundary value problem, describes both the phenomena. Only a few of solutions of those problems were found in an exact form. An analytical solution can be obtained only for not very complex boundary conditions and for bodies of simple shapes like rectangle, circle, cylinder etc. The solutions of both heat conduction and diffusion problems are not so easy to find for bodies of more complex shapes. In those cases the numerical or approximate methods have to be applied. In this paper we restrict to a method of integral equations, which often is used in the electromagnetic theory. For the sake of simplicity only heat conduction theory is considered, because it is reduced to the special class of integral equations in space-time, called Volterra-Fredholm integral equations [2, 3, 4]. In this section we will present certain mathematical models in the heat conduction leading to these integral equations [8].

\subsection{First Fourier's problem in heat conduction theory}

Heat conduction equation is defined by

$$
\Delta T-\frac{1}{a^{2}} \frac{\partial T}{\partial t}=0
$$

where $\Delta=\sum_{j=1}^{m} \frac{\partial^{2}}{\partial x_{j}^{2}}, a$ is a certain physical constant, $T$ means temperature at time $t$ in point $x=\left(x_{1}, x_{2}, \ldots, x_{m}\right), m \geq 2$ of the considered domain $D$ with border $S$ being closed surface of the class $C^{2}$.

Let us notice that a function

$$
w(x, t)=a^{2}\left(4 a^{2} \pi t\right)^{-\frac{m}{2}} \exp \left(-\frac{|x|^{2}}{4 a^{2} t}\right)
$$

defined for $t>0$ is a fundamental solution of equation (4.1).

The first internal Fourier's problem is to find function $T$ satisfying equation (4.1) and the following initial-boundary conditions in domain $D_{i}$

$$
\begin{aligned}
& T_{i}(\xi, t)=\Psi(\xi, t), \\
& \lim _{t \rightarrow 0+} T(x, t)=\varphi(x),
\end{aligned}
$$

where $\Psi, \varphi$ are given bounded and continuous functions on $D_{i}$ and $S$, respectively.

Then the temperature $T$ is given by formula

$$
T(x, t)=\frac{1}{a^{2}} \int_{D_{i}} \varphi(y) w(x-y, t) d y+\int_{0}^{t} \int_{S} f(\eta, \tau) \frac{\partial}{\partial n_{\eta}} w(x-\eta, t-\tau) d S_{\eta} d \tau,
$$


where the density function $f$ is a solution of the integral equation

$$
f(\xi, t)+\int_{0}^{t} \int_{S} N(\xi, t, \eta, \tau) f(\eta, \tau) d S_{\eta} d \tau=g(\xi, t)
$$

with a kernel $N$ of the form

$$
N(\xi, t, \eta, \tau)=2 \frac{\partial}{\partial n_{\eta}} w(\xi-\eta, t-\tau)=\frac{|\xi-\eta| \cos \left(\xi-\eta, \eta_{\eta}\right)}{a^{2}(t-\tau)} w(\xi-\eta, t-\tau),
$$

where $\xi-\eta$ means a vector starting at the point $\eta$ and finishing at the point $\xi$ and function $g$ is given by

$$
g(\xi, t)=2 \Psi(\xi, t)-\frac{2}{a^{2}} \int_{D_{i}} \varphi(y) w(\xi-y, t) d y .
$$

The first external Fourier's problem leads to solve equation (4.1) with the following conditions

$$
\begin{aligned}
& T_{e}(\xi, t)=\Psi(\xi, t) \quad t>0, \quad \xi \in S, \\
& \lim _{t \rightarrow 0+} T(x, t)=\varphi(x),
\end{aligned}
$$

where $\Psi, \varphi$ are the given bounded and continuous functions on $D_{e}$ and $S \times$ $(0, \infty)$, respectively.

Then a solution of this problem is given by formula (4.2), where the density-function is calculated from the following integral equation

$$
f(\xi, t)-\int_{0}^{t} \int_{S} N(\xi, t, \eta, \tau) f(\eta, \tau) d S_{\eta} d \tau=\tilde{g}(\xi, t)
$$

with

$$
\tilde{g}(\xi, t)=-2 \Psi(\xi, t)-\frac{2}{a^{2}} \int_{D_{e}} \varphi(y) w(\xi-y, t) d y
$$

and the kernel $N$ is defined by formula (4.3).

\subsection{Second Fourier's problem in the heat conduction theory}

Second interior Fourier's problem for equation (4.1) is defined by the following boundary-initial conditions

$$
\begin{aligned}
& \left(\frac{\partial T}{\partial n_{\xi}}\right)_{i}(\xi, t)=\Psi(\xi, t) \quad t>0, \quad \xi \in S, \\
& \lim _{t \rightarrow 0+} T(x, t)=\varphi(x),
\end{aligned}
$$


where $\varphi, \Psi$ are the given bounded and continuous functions on $D_{i}, S$, respectively. It leads to the following solution

$$
T(x, t)=\frac{1}{a^{2}} \int_{D_{e}} \varphi(y) w(x-y, t) d y+\iint_{0}^{t} f(\eta, \tau) w(x-\eta, t-\tau) d S_{\eta} d \tau .
$$

The density-function $f$ is a solution of the integral equation

$$
f(\xi, t)-\int_{0}^{t} \int_{S} N^{*}(\xi, t, \eta, \tau) f(\eta, \tau) d S_{\eta} d \tau=k(\xi, t)
$$

with

$$
N^{*}(\xi, t, \eta, \tau)=2 \frac{\partial}{\partial n_{\xi}} w(\xi-\eta, t-\tau)=\frac{|\xi-\eta| \cos \left(\eta-\xi, \eta_{\xi}\right)}{a^{2}(t-\tau)} w(\xi-\eta, t-\tau),
$$

and

$$
k(\xi, t)=-2 \Psi(\xi, t)+\frac{2}{a^{2}} \int_{D_{e}} \varphi(y) \frac{\partial}{\partial n_{\xi}} w(\xi-y, t) d y .
$$

The second external Fourier's problem consists to find the solution of equation (4.1) with the boundary-initial conditions in domain $D_{e}$

$$
\begin{aligned}
& \left(\frac{\partial T}{\partial n_{\xi}}\right)_{e}(\xi, t)=\Psi(\xi, t) \quad t>0, \\
& \lim _{t \rightarrow 0+} T(x, t)=\varphi(x),
\end{aligned}
$$

where $\varphi, \Psi$ are known given functions. Then a solution of this boundary-initial value problem is defined by formula (4.4) with the density-function satisfying the integral equation

$$
f(\xi, t)+\int_{0}^{t} \int_{S} N^{*}(\xi, t, \eta, \tau) f(\eta, \tau) d S_{\eta} d \tau=\tilde{k}(\xi, t)
$$

with

$$
\tilde{k}(\xi, t)=2 \Psi(\xi, t)-\frac{1}{a^{2}} \int_{D_{e}} \varphi(y) \frac{\partial}{\partial n_{\xi}} w(\xi-y, t) d y
$$

and the kernel $N^{*}$ is defined by (4.5).

\section{Numerical Method for Integral Equation in Space-Time}

The current density problems were reduced to the system of integro-differential equations of the Fredholm type, which after discretization in time gives the 
system of algebraic equations [5]. It is possible to reduce the mathematical model in the current density to the following integral equations in space-time

$$
u(x, t)=f(x, t)+\int_{0}^{t} \int_{M} k(x, t, y, s) u(y, s) d y d s .
$$

This equation arise also in the mathematical model of the heat-conduction theory.

In this section we consider that integral equation in space-time, where $f$ is a given function in domain $D=M \times[0, T]$ ( $M$ is a compact subset of $m$-dimensional Euclidean space) and $u$ is unknown function in $D$. The given kernel $k$ is defined in domain

$$
\Omega=\{(x, t, y, s): x, y \in M, 0 \leq s \leq t \leq T\} .
$$

Numerical methods for these equations were presented in papers $[2,3,4]$. In the next section we propose a new numerical method for equation

$$
u=f+K u,
$$

where

$$
(K u)(x, t)=\int_{0}^{t} \int_{a}^{b} k(x, t, y, s) u(y, s) d y d s
$$

\subsection{Presentation of the method}

From a numerical point of view the method of successive approximations is not efficient. Then we can introduce some corrections to obtain the following method

$$
u_{k}=f+K\left(u_{k-1}+c_{n}\right),
$$

where $c_{n}$ can be defined in various ways.

We restrict our presentation to the following integral equation

$$
u(x, t)=f(x, t)+\int_{0}^{t} \int_{0}^{b} k(x, t, y, s) u(y, s) d y d s
$$

where the given functions $f$ and $k$ are defined in domains $D=[a, b] \times[0, T]$ and

$$
\Omega=\{(x, t, y, s): a \leq x, y \leq b, 0 \leq s \leq t \leq T\} .
$$

We seek approximate solution of equation (5.1) in the following form

$$
u_{k}(x, t)=f(x, t)+\int_{0}^{t} \int_{0}^{b} k(x, t, y, s)\left[u_{k-1}(y, s)+p_{k}^{n}(y, s)\right] d y d s, k=1,2,3, \ldots
$$


where

$$
p_{k}^{n}(x, t)=\sum_{j=0}^{n} a_{j k}(t) \varphi_{j}(x),
$$

$u_{0}$ is any function defined on interval $[a, b] \times[0, T]$ and $\varphi_{j}$ are some basis functions. Unknown coefficients $a_{j k}$ satisfy the following conditions:

$$
p_{k}^{n}\left(x_{j}, t\right)=\Delta u_{k}\left(x_{j}, t\right), \quad k=1,2, \ldots,
$$

where

$$
\Delta u_{k}\left(x_{j}, t\right)=u_{k}\left(x_{j}, t\right)-u_{k-1}\left(x_{j}, t\right), \quad j=0,1, \ldots, n,
$$

and $x_{j}$ are collocation points such that

$$
\varphi_{i}\left(x_{j}\right)=\left\{\begin{array}{l}
1, \text { for } i=j \\
0, \text { for } i \neq j
\end{array}\right.
$$

Basis functions $\varphi_{i}, i=0,1, \ldots, n$ can be defined as Lagrange fundamental polynomials

$$
l_{i}(x)=\frac{\left(x-x_{0}\right)\left(x-x_{1}\right) \ldots\left(x-x_{i-1}\right)\left(x-x_{i+1}\right) \ldots\left(x-x_{n}\right)}{\left(x_{i}-x_{0}\right)\left(x_{i}-x_{1}\right) \ldots\left(x_{i}-x_{i-1}\right)\left(x_{i}-x_{i+1}\right) \ldots\left(x_{i}-x_{n}\right)} .
$$

From (5.3) and (5.4) we get

$$
p_{k}^{n}\left(x_{j}, t\right)=a_{j k}(t)
$$

Then

$$
p_{k}^{n}(x, t)=\sum_{j=0}^{n} p_{k}^{n}\left(x_{j}, t\right) \varphi_{j}(x)
$$

is a collocation polynomial of the Lagrange type with respect to variable $x$ for almost every $t \in[0, T]$. From $(5.3),(5.4)$ and (5.1) we get

$$
a_{j k}(t)=g_{j k}(t)+\int_{0}^{t} \int_{a}^{b} k\left(x_{j}, t, y, s\right) p_{k}^{n}(y, s) d y d s
$$

where

$$
g_{j k}(t)=\int_{0}^{t} \int_{a}^{b} k\left(x_{j}, t, y, s\right)\left[u_{k-1}(y, s)-u_{k-2}(y, s)-p_{k-1}^{n}(y, s)\right] d y d s .
$$

Introducing the notation

$$
c_{i j}(t, s)=\int_{a}^{b} k\left(x_{j}, t, y, s\right) \varphi_{i}(y) d y
$$

we obtain the system of linear integral equations of the Volterra type of the second kind 


$$
a_{j k}(t)=g_{j k}(t)+\sum_{i=0}^{n} \int_{0}^{t} c_{i j}(t, s) a_{i k}(s) d s
$$

with unknown functions $a_{0 k}, a_{1 k}, a_{2 k}, \ldots, a_{n k}$ and given $g_{0 k}, g_{1 k}, g_{2 k}, \ldots, g_{n k}$, $c_{i j}, i, j=0,1, \ldots, n$. Let us introduce notation:

$$
k_{n}(x, t, y, s)=\sum_{j=0}^{n} k\left(x_{j}, t, y, s\right) \varphi_{j}(x),
$$

where points $x_{j}(j=0,1, \ldots, n)$ are zeros of some orthogonal polynomials.

Let $R$ be a space of the Riemann integrable functions on $D$ with a norm

$$
\|u\|_{R}=\sup _{(x, t) \in D}\{|u(x, t)|\} .
$$

Let $w(x)$ be a bounded and positive weight-function, then $L_{w}^{2}, L^{2}$ are spaces provided with the norms

$$
\|u\|_{L_{w}^{2}}=\left(\int_{0}^{T} \int_{a}^{b}|u(x, t)|^{2} w(x) d x d t\right)^{1 / 2}, \quad\|u\|_{L^{2}}=\left(\int_{0}^{T} \int_{a}^{b}|u(x, t)|^{2} d x d t\right)^{1 / 2} .
$$

Remark 3. [2] Integral equation (5.1) has a unique solution for $g \in R(D)$ and $k \in C(\Omega)$ of the form

$$
\begin{aligned}
& u(x, t)=g(x, t)+\int_{0}^{t} \int_{a}^{b} r(x, t, y, s) g(y, s) d y d s, \\
& r(x, t, y, s)=\sum_{n=1}^{\infty} k_{(n)}(x, t, y, s),
\end{aligned}
$$

where iterated kernels are defined in the following way:

$$
\begin{aligned}
& k_{(n)}(x, t, y, s)=\int_{0}^{t} \int_{a}^{b} k(x, t, z, w) k_{(n-1)}(z, w, y, s) d z d w, \text { for } n=2,3, \ldots \\
& k_{(1)}(x, t, y, s)=k(x, t, y, s) .
\end{aligned}
$$

Lemma 1. [7] If $u(x) \in R[a, b]$, then

$$
\left\|p^{n} u-u\right\|=\left[\int_{a}^{b}\left|p^{n} u(x)-u(x)\right|^{2} w(x) d x\right]^{1 / 2} \rightarrow 0 \quad \text { for } n \rightarrow \infty,
$$

where 


$$
p^{n} u(x)=\sum_{i=0}^{n} u\left(x_{i}\right) \varphi_{i}(x)
$$

is an interpolation polynomial of the Lagrange type with the knots $x_{i}, i=$ $0,1, \ldots, n$ being zeros of some orthogonal polynomials with the weight-function $w(x)$ in $[a, b]$ and Lagrange basis functions $\varphi_{i}(x)$.

Theorem 1. Let the following assumptions

a) points $x_{j}(i=0,1,2, \ldots, n)$ are zeros of an orthogonal polynomials with weight-function $w(x)$ in $[a, b]$,

b) $\Delta u_{k}$ is a Riemann integrable function in $D$

are satisfied. Then

$$
\left\|p_{k}^{n}-\Delta u_{k}\right\|_{L_{w}^{2}} \rightarrow 0 \quad \text { if } n \rightarrow \infty
$$

where

$$
p_{k}^{n}(x, t)=\sum_{i=0}^{n} \Delta u_{k}\left(x_{i}, t\right) \varphi_{i}(x)
$$

is an interpolation polynomial of the Lagrange type with respect to variable $x$ built on the knots $x_{i}$ and the basis functions $l_{i}(x), i=0,1,2, \ldots, n$.

Proof. By lemma we obtain

$$
\left\|p_{k}^{n}(\cdot, t)-\Delta u_{k}(\cdot, t)\right\| \rightarrow 0 \text { if } n \rightarrow \infty \text { for almost every } t \in[0, T] .
$$

Introducing the notation

$$
\left\|p_{k}^{n}(\cdot, t)-\Delta u_{k}(\cdot, t)\right\|^{2}=W_{n}^{2}(t)
$$

we get

$$
W_{n}^{2}(t)=\int_{a}^{b}\left|p_{k}^{n}(x, t)-\Delta u_{k}(x, t)\right|^{2} w(x) d x \rightarrow 0, \text { if } n \rightarrow \infty
$$

Then (see [8])

$$
\int_{0}^{T} W_{n}^{2}(t) d t=\int_{0}^{T} \int_{a}^{b}\left|p_{k}^{n}(x, t)-\Delta u_{k}(x, t)\right|^{2} w(x) d x d t \rightarrow 0,
$$

and

$$
\left\|W_{n}\right\|_{L^{2}}^{2}=\left\|p_{k}^{n}-\Delta u_{k}\right\|_{L_{w}^{2}}^{2} \rightarrow \infty \quad \text { for } n \rightarrow \infty
$$

Hence

$$
\left\|p_{k}^{n}-\Delta u_{k}\right\|_{L_{w}^{2}}^{2} \rightarrow 0 \quad \text { if } n \rightarrow \infty
$$


Theorem 2. If $u \in R(D)$ and

$$
C=\sup _{(x, t) \in D} \int_{0}^{t} \int_{a}^{b} \frac{|k(x, t, y, s)|^{2}}{w(y)} d y d s<\infty
$$

then

$$
q_{n}=\frac{K_{n} M}{1-M K_{n}} \stackrel{n \rightarrow \infty}{\longrightarrow} 0
$$

where $M=1+N$ and

$$
\begin{gathered}
N=\iint_{0}^{T} \int_{a}^{b} \int_{a}^{t} \frac{|r(x, t, y, s)|^{2}}{w(y)} w(x) d y d s d x d t, \\
K_{n}=\iint_{0} \int_{0} \int_{0}^{b} \frac{\left|k_{n}(x, t, y, s)-k(x, t, y, s)\right|^{2}}{w(y)} w(x) d y d s d x d t,
\end{gathered}
$$

and the sequence $\left\{u_{k}\right\}$ defined by formula (5.2) tends to unique solution of equation (5.1); moreover, the following estimates
a) $\left\|u_{k}-u\right\|_{R} \leq C q_{n}^{k-1}\left\|V_{1}\right\|_{L_{w}^{2}}$
b) $\left\|u_{k}-u\right\|_{L_{w}^{2}} \leq L q_{n}^{k-1}\left\|V_{1}\right\|_{L_{w}^{2}}$

hold, where

$$
L=\int_{0}^{T} \int_{a} \int_{0}^{b} \int_{a}^{b} \frac{|k(x, t, y, s)|^{2}}{w(y)} w(x) d y d s d x d t .
$$

Sketch of the proof. From the presented method we get

$p_{k}^{n}(x, t)=\int_{0}^{t} \int_{a}^{b} k_{n}(x, t, y, s)\left[u_{k-1}(y, s)-u_{k-2}(y, s)+p_{k}^{n}(y, s)-p_{k-1}^{n}(y, s)\right] d y d s$.

After some calculations we can prove that $V_{k}$ defined by the formula

$$
V_{k}(y, s)=u(y, s)-u_{k-1}(y, s)-p_{k}^{n}(y, s), \quad k=1,2, \ldots
$$

satisfies the Volterra-Fredholm integral equation

$$
V_{k}(x, t)=g_{k}(x, t)+\int_{0}^{t} \int_{a}^{b} k(x, t, y, s) V_{k}(y, s) d y d s
$$

where $g_{k}$ is given by the formula

$$
g_{k}(x, t)=\int_{0}^{t} \int_{a}^{b}\left[k_{n}(x, t, y, s)-k(x, t, y, s)\right]\left[V_{k}(y, s)-V_{k-1}(y, s)\right] d y d s .
$$


By Remark 3 the solution of the above equation can be described in the form

$$
V_{k}(x, t)=g_{k}(x, t)+\int_{0}^{t} \int_{a}^{b} r(x, t, y, s) g_{k}(y, s) d y d s,
$$

then

$$
\left\|V_{k}\right\|_{L_{w}^{2}} \leq\left\|g_{k}\right\|_{L_{w}^{2}}(1+N)
$$

Hence we get the following estimates

$$
\left\|g_{k}\right\|_{L_{w}^{2}} \leq\left(\left\|V_{k}\right\|_{L_{w}^{2}}+\left\|V_{k-1}\right\|_{L_{w}^{2}}\right) K_{n}, \quad\left\|V_{k}\right\|_{L_{w}^{2}} \leq q_{n}\left\|V_{k-1}\right\|_{L_{w}^{2}} .
$$

By the mathematical induction we obtain

$$
\left\|V_{k}\right\|_{L_{w}^{2}} \leq q_{n}^{k-1}\left\|V_{1}\right\|_{L_{w}^{2}} .
$$

The convergence of the method follows from Theorem 1, because

$$
\left\|k_{n}-k\right\|_{L^{2}} \stackrel{n \rightarrow \infty}{\longrightarrow} 0 \text {. }
$$

We get the estimates a), b) by subtraction (5.1) and (5.2) and using (5.6). Then

$$
\left|u_{k}(x, t)-u(x, t)\right|=\left|\iint_{0}^{t} \int_{a}^{b} k(x, t, y, s) V_{k}(y, s) d y d s\right| .
$$

From the Buniakowski-Schwarz inequality we obtain

$$
\left\|u_{k}-u\right\|_{R} \leq C\left\|V_{k}\right\|_{L_{w}^{2}}, \quad\left\|u_{k}-u\right\|_{L_{w}^{2}} \leq L\left\|V_{k}\right\|_{L_{w}^{2}} .
$$

By (5.7) we have estimates a) and b), respectively.

\section{Numerical Experiments}

In the presented method the corrections $p_{k}^{n}$ are determined from the system of Volterra integral equations (5.5). In the collocation-iterative method (see [4]) the corrections have constant coefficients calculated from an algebraic system. The given tables contain relative errors $\delta$ of the solution at points $t_{j}$ and $x_{j}$ :

$$
\delta=\left|\frac{u_{k}\left(x_{i}, t_{j}\right)-u\left(x_{i}, t_{j}\right)}{u\left(x_{i}, t_{j}\right)}\right| .
$$

Here $n+1$ means a number of basis functions and $k$ is a number of iterations. Fundamental Lagrange polynomials are used as basis functions.

Example 1.

$$
\begin{aligned}
& u(x, t)=\sin \left(\frac{t \pi}{2}\right)\left[e^{x}-\sin \left(\frac{t \pi}{2}\right)\right]+\int_{0}^{t} \int_{-1}^{1} \frac{\pi}{2} e^{-y} \cos \left(\frac{s \pi}{2}\right) u(y, s) d y d s, \\
& n=5, \quad k=10 .
\end{aligned}
$$


Table 1. Relative errors for the first test function.

\begin{tabular}{lllllll}
\hline-1 & $-0,4$ & $-0,2$ & 0,2 & 0,4 & 1 & $x \backslash t$ \\
\hline $0,428 \cdot 10^{-2}$ & $0,287 \cdot 10^{-2}$ & $0,192 \cdot 10^{-3}$ & $0,129 \cdot 10^{-2}$ & $0,864 \cdot 10^{-3}$ & $0,579 \cdot 10^{-3}$ & 0,1 \\
$0,933 \cdot 10^{-2}$ & $0,626 \cdot 10^{-2}$ & $0,419 \cdot 10^{-2}$ & $0,281 \cdot 10^{-2}$ & $0,188 \cdot 10^{-2}$ & $0,126 \cdot 10^{-2}$ & 0,2 \\
$0,154 \cdot 10^{-1}$ & $0,103 \cdot 10^{-1}$ & $0,690 \cdot 10^{-2}$ & $0,463 \cdot 10^{-2}$ & $0,310 \cdot 10^{-2}$ & $0,208 \cdot 10^{-2}$ & 0,3 \\
$0,280 \cdot 10^{-1}$ & $0,148 \cdot 10^{-1}$ & $0,989 \cdot 10^{-2}$ & $0,663 \cdot 10^{-2}$ & $0,444 \cdot 10^{-2}$ & $0,298 \cdot 10^{-2}$ & 0,4 \\
$0,311 \cdot 10^{-1}$ & $0,188 \cdot 10^{-1}$ & $0,126 \cdot 10^{-1}$ & $0,846 \cdot 10^{-2}$ & $0,567 \cdot 10^{-2}$ & $0,380 \cdot 10^{-2}$ & 0,5 \\
$0,280 \cdot 10^{-1}$ & $0,208 \cdot 10^{-1}$ & $0,139 \cdot 10^{-1}$ & $0,936 \cdot 10^{-2}$ & $0,628 \cdot 10^{-2}$ & $0,421 \cdot 10^{-2}$ & 0,6 \\
$0,182 \cdot 10^{-1}$ & $0,188 \cdot 10^{-1}$ & $0,125 \cdot 10^{-1}$ & $0,843 \cdot 10^{-2}$ & $0,565 \cdot 10^{-2}$ & $0,379 \cdot 10^{-2}$ & 0,7 \\
$0,672 \cdot 10^{-1}$ & $0,122 \cdot 10^{-1}$ & $0,819 \cdot 10^{-2}$ & $0,549 \cdot 10^{-2}$ & $0,368 \cdot 10^{-2}$ & $0,247 \cdot 10^{-2}$ & 0,8 \\
$0,153 \cdot 10^{-2}$ & $0,451 \cdot 10^{-2}$ & $0,302 \cdot 10^{-2}$ & $0,202 \cdot 10^{-2}$ & $0,136 \cdot 10^{-2}$ & $0,910 \cdot 10^{-2}$ & 0,9 \\
$0,234 \cdot 10^{-2}$ & $0,103 \cdot 10^{-1}$ & $0,688 \cdot 10^{-3}$ & $0,461 \cdot 10^{-3}$ & $0,309 \cdot 10^{-3}$ & $0,207 \cdot 10^{-3}$ & 1 \\
\hline
\end{tabular}

Example 2.

$$
\begin{aligned}
& u(x, t)=x^{2}\left(e^{-t}-\frac{2}{3} t^{3}\right)+\int_{0-1}^{t} \int_{-1}^{1} x^{2} t^{2} e^{s} u(y, s) d y d s, \\
& n=5, \quad k=7
\end{aligned}
$$

\section{The new method}

Table 2. Relative errors for the new method.

\begin{tabular}{lllllll}
\hline-1 & $-0,4$ & $-0,2$ & 0,2 & 0,4 & 1 & $x \backslash t$ \\
\hline $0,109 \cdot 10^{-25}$ & $0,109 \cdot 10^{-25}$ & $0,109 \cdot 10^{-25}$ & $0,109 \cdot 10^{-25}$ & $0,109 \cdot 10^{-25}$ & $0,109 \cdot 10^{-25}$ & 0,1 \\
$0,413 \cdot 10^{-20}$ & $0,413 \cdot 10^{-20}$ & $0,413 \cdot 10^{-20}$ & $0,413 \cdot 10^{-20}$ & $0,413 \cdot 10^{-20}$ & $0,413 \cdot 10^{-20}$ & 0,2 \\
$0,146 \cdot 10^{-14}$ & $0,146 \cdot 10^{-14}$ & $0,146 \cdot 10^{-14}$ & $0,146 \cdot 10^{-14}$ & $0,146 \cdot 10^{-14}$ & $0,146 \cdot 10^{-14}$ & 0,3 \\
$0,743 \cdot 10^{-11}$ & $0,743 \cdot 10^{-11}$ & $0,743 \cdot 10^{-11}$ & $0,743 \cdot 10^{-11}$ & $0,743 \cdot 10^{-11}$ & $0,743 \cdot 10^{-11}$ & 0,4 \\
$0,129 \cdot 10^{-9}$ & $0,129 \cdot 10^{-9}$ & $0,129 \cdot 10^{-9}$ & $0,129 \cdot 10^{-9}$ & $0,129 \cdot 10^{-9}$ & $0,129 \cdot 10^{-9}$ & 0,5 \\
$0,112 \cdot 10^{-8}$ & $0,112 \cdot 10^{-8}$ & $0,112 \cdot 10^{-8}$ & $0,112 \cdot 10^{-8}$ & $0,112 \cdot 10^{-8}$ & $0,112 \cdot 10^{-8}$ & 0,6 \\
$0,609 \cdot 10^{-8}$ & $0,609 \cdot 10^{-8}$ & $0,609 \cdot 10^{-8}$ & $0,609 \cdot 10^{-8}$ & $0,609 \cdot 10^{-8}$ & $0,609 \cdot 10^{-8}$ & 0,7 \\
$0,242 \cdot 10^{-6}$ & $0,242 \cdot 10^{-6}$ & $0,242 \cdot 10^{-6}$ & $0,242 \cdot 10^{-6}$ & $0,242 \cdot 10^{-6}$ & $0,242 \cdot 10^{-6}$ & 0,8 \\
$0,793 \cdot 10^{-5}$ & $0,793 \cdot 10^{-5}$ & $0,793 \cdot 10^{-5}$ & $0,793 \cdot 10^{-5}$ & $0,793 \cdot 10^{-5}$ & $0,793 \cdot 10^{-5}$ & 0,9 \\
$0,242 \cdot 10^{-3}$ & $0,242 \cdot 10^{-3}$ & $0,242 \cdot 10^{-3}$ & $0,242 \cdot 10^{-3}$ & $0,242 \cdot 10^{-3}$ & $0,242 \cdot 10^{-3}$ & 1 \\
\hline
\end{tabular}




\section{Collocation-iterative method [4]}

Table 3. Relative errors for the collocation-iterative method.

\begin{tabular}{lllllll}
\hline-1 & $-0,4$ & $-0,2$ & 0,2 & 0,4 & 1 & $x \backslash t$ \\
\hline $0,221 \cdot 10^{-9}$ & $0,614 \cdot 10^{-9}$ & $0,304 \cdot 10^{-9}$ & $0,221 \cdot 10^{-9}$ & $0,614 \cdot 10^{-9}$ & $0,304 \cdot 10^{-9}$ & 0,1 \\
$0,361 \cdot 10^{-8}$ & $0,341 \cdot 10^{-8}$ & $0,344 \cdot 10^{-8}$ & $0,361 \cdot 10^{-8}$ & $0,341 \cdot 10^{-8}$ & $0,344 \cdot 10^{-8}$ & 0,2 \\
$0,137 \cdot 10^{-7}$ & $0,140 \cdot 10^{-7}$ & $0,138 \cdot 10^{-7}$ & $0,137 \cdot 10^{-7}$ & $0,140 \cdot 10^{-7}$ & $0,138 \cdot 10^{-7}$ & 0,3 \\
$0,283 \cdot 10^{-7}$ & $0,280 \cdot 10^{-7}$ & $0,273 \cdot 10^{-7}$ & $0,283 \cdot 10^{-7}$ & $0,280 \cdot 10^{-7}$ & $0,273 \cdot 10^{-7}$ & 0,4 \\
$0,419 \cdot 10^{-7}$ & $0,419 \cdot 10^{-7}$ & $0,437 \cdot 10^{-7}$ & $0,419 \cdot 10^{-7}$ & $0,419 \cdot 10^{-7}$ & $0,437 \cdot 10^{-7}$ & 0,5 \\
$0,538 \cdot 10^{-7}$ & $0,678 \cdot 10^{-7}$ & $0,462 \cdot 10^{-7}$ & $0,538 \cdot 10^{-7}$ & $0,678 \cdot 10^{-7}$ & $0,462 \cdot 10^{-7}$ & 0,6 \\
$0,750 \cdot 10^{-7}$ & $0,901 \cdot 10^{-7}$ & $0,500 \cdot 10^{-7}$ & $0,750 \cdot 10^{-7}$ & $0,901 \cdot 10^{-7}$ & $0,500 \cdot 10^{-7}$ & 0,7 \\
$0,152 \cdot 10^{-6}$ & $0,136 \cdot 10^{-6}$ & $0,164 \cdot 10^{-6}$ & $0,152 \cdot 10^{-6}$ & $0,136 \cdot 10^{-6}$ & $0,164 \cdot 10^{-6}$ & 0,8 \\
$0,171 \cdot 10^{-6}$ & $0,428 \cdot 10^{-6}$ & $0,600 \cdot 10^{-6}$ & $0,171 \cdot 10^{-6}$ & $0,428 \cdot 10^{-6}$ & $0,600 \cdot 10^{-6}$ & 0,9 \\
$0,291 \cdot 10^{-5}$ & $0,164 \cdot 10^{-5}$ & $0,165 \cdot 10^{-5}$ & $0,291 \cdot 10^{-5}$ & $0,164 \cdot 10^{-5}$ & $0,165 \cdot 10^{-5}$ & 1 \\
\hline
\end{tabular}

\section{Conclusions}

The main result of this paper is an analysis of the new numerical method for general class of integral equations in space-time. Some problems of electrical engineering are reducible to such type of equations. Sketch of the proof for the convergence of the presented method is given and estimates of an error are established. This theory is illustrated by two numerical examples and their comparison is made by computational results. Second example gives better results for the presented method than the method studied in [4].

\section{References}

[1] K. Domke and J. Hauser. Calculation of radiant flux transfer using the ray tracing method. Computers in Electrical Engineering, 115 - 125, 2005. Monograph ZKwE (Poznan University of Technology)

[2] L. Hącia. Computational methods for Volterra-Fredholm integral equations. Computational Methods in Science and Technology, 8(2), 13 - 26, 2002.

[3] L. Hạcia. Projection methods for integral equations in epidemic. Mathematical Modelling and Analysis, 7(2), 229 - 240, 2002.

[4] L. Hącia. Integral equations in some problems of electrotechnics. In: Lecture 4th International Conference APLIMAT, Bratislava, 153 - 164, February 1-4, 2005. (Plenary Lecture)

[5] L. Hạcia and A. Patecki. Analysis of the current density in the conductor by integro-differential equations. In: VIII Conference on Applications of Computers in Electrical Engineering, Poznan Kiekrz, 159 - 162, April 7-9, 2003. (In Polish)

[6] M. Krakowski. Theoretical electrical engineering, V. 2. Electromagnetic fields, PWN, Warsaw, 1999. (In Polish) 
[7] E.M. Lucev. Collocation-iterative method of solving linear integral equations second kind. Investigation methods for differential and integral equations, Kiev (Naukova Dumka), 132 - 138, 1989. (In Russian)

[8] A. Piskorek. Integral equations - theory and applications. PWN, Warsaw, 1997. (in Polish)

\section{Matematinis modeliavimas elektros inžinerijoje}

L. Hącia

Daugelio elektros inžinerijos problemų sprendimui tenka sudaryti matematinius modelius, kurie dažniausiai būna aprašomi skirtuminèmis, diferencialinèmis ar integralinėmis lygtimis. Šiame darbe apžvelgiami kai kurie modeliai, skirti konkrečiu elektros inžinerijos uždavinių sprendimui. Apsiribojama šilumos perdavimo proceso su spinduliuote modeliavimu ir tankio pasiskirstymo teorija (Fredholmo integralinès lygtys).İvedus laiką, lygtys tankiui tampa integr-diferencialinèmis arba VolterosFredholmo integralinèmis lygtimis. Darbe pateikiamas ir nagrinėjamas naujas skaitinis tokių lygčiu sprendimo metodas. 